\title{
Experience of the Crane Steel Wire Ropes Non-Destructive Tests
}

\author{
Pavel Peterka ${ }^{1 *}$, Jozef Krešák ${ }^{1}$, Marek Vojtko² \\ 1 Technical University of Košice, Faculty of mining, ecology, process control and geotechnology, Testing \\ laboratory of steel wire ropes, Park Komenského 14, 04384 Košice, Slovak Republic \\ 2 Institute of Materials Research, Slovak Academy of Science, Watsonova 47, 04001 Košice, Slovak Republic \\ * Corresponding author's e-mail: pavel.peterka@tuke.sk
}

\begin{abstract}
The non-destructive tests (NDT) of the steel wire ropes put on the crane pulley blocks comprise more than a half of our NDT services. The intensive utilization of cranes often leads to critical situations endangering health and safety at work. The operators are forced to provide safety use of the cranes due to new cranes constructions, new construction of the block pulley and put on the new steel wire rope constructions. The NDT tests of the crane steel wire ropes are coordinate by the Standard ISO 4309. We have experienced only the crane steel wire ropes with an individual wire rope core during our NDT tests so far. The visual NDT test usually used is ineffective to the steel wire ropes with this construction. Based on our previous experience it can be confirmed that surface ruptures are produced after the disintegration of wires inside of a rope; it often leads to the rope abruption during its operation. The reduction of the pulley block dimensions often leads to the problem of the multi-axis rope bending. This kind of the rope line in the pulley block causes the increase of the fretting fatigue of the wires and the rope strands. The same type of the stress is created when the dead ends of the rope are badly constructed.
\end{abstract}

Keywords: steel wire ropes, crane, quality, failure analysis.

\section{INTRODUCTION}

Steel ropes are complex flexible structures used in many technical applications, such as elevators [1], crane [2, 3, 4], marine applications [5], cable ways and hoisting mine applications $[6,7]$. In many high-rise residential buildings or multistorey warehouses, machinery, so called lifts, are used for the vertical transportation of people or weights between attitudinally distant places [8].

Due to the specific design and critical safety requirements, diagnostics of ropes remains an important issue. Broken wire number in the steel ropes is limited by safety standards when they are used in the human lifting and carrying installations $[9 \div 14]$. The broken wires increase the stress in the inner wire strands as well as the contact force between the wires. This leads to a concentration of severe wear which accelerates the density of broken wires locally leading to short fatigue lives especially in the case with the most concen- trated number of pre-broken wires $[15 \div 19]$. For the crack initiation mechanism of anodic dissolution, the stronger the corrosivity of solution was, the more easily the fatigue crack source formed, while, for the crack initiation mechanism of deformation activation, the lower stress ratio and higher frequency would accelerate the generation of corrosion fatigue crack source [20]. Wear is one of the primary factors for the degradation of the wire rope used for multi-layer winding hoist. It decreases the carrying capacity and service life of the hoisting rope, which will affect the mine safety directly [21]. The increase in the longitudinal rope vibration will reduce the friction force between the rope and lining [22]. The limitation for transverse vibration displacement of wire rope becomes stronger, and the effect is fading when the rigidity reaches a certain value $[23,24]$.

Changing the value of acceleration and velocity in the lifting process, variation rule of rope tension and deformation in the lifting process, the 


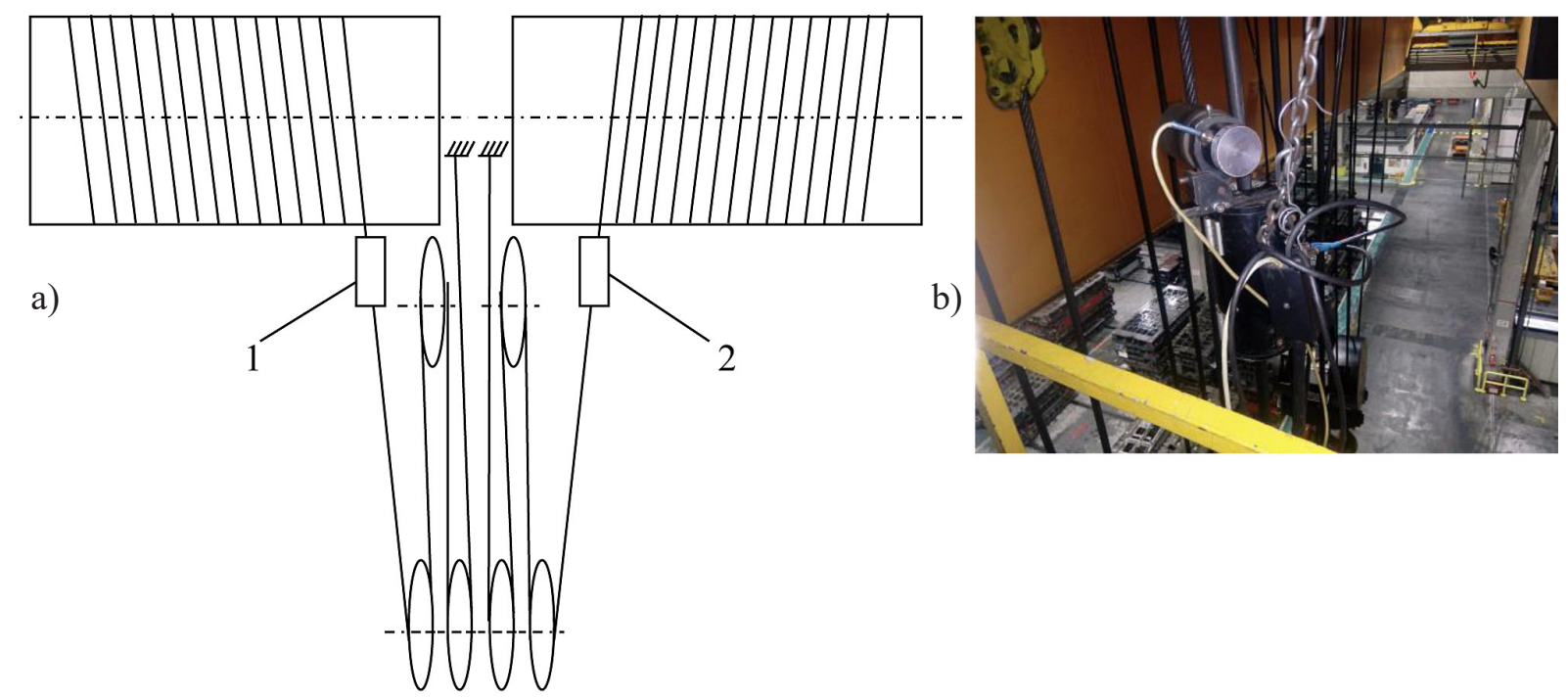

Fig. 1. (a) Pulley crane system, positions 1); 2) are the points where the defectoscopic device was stepped; b) Mounting of the defectoscopic device to the crane rope

influence on tension and deformation and vibration frequency from acceleration and velocity are subject to $[25,26]$.

The coefficient of friction of the wire rope changes little with increasing load and stabilizes, but decreases with the sliding velocity under dryfriction condition [27]. The friction element can capture the sliding among different wires [28]. The results of the tests show that the coefficient of friction (COF) of the wire rope changes little with increasing load and stabilizes at approximately 0.73 , but decreases with the sliding velocity under dry-friction condition [29].

The application of finite-element method when investigating the stress-strain state of a work piece exposed to the gauge burnishing under the conditions of nonzero friction is considered $[30 \div 33]$.

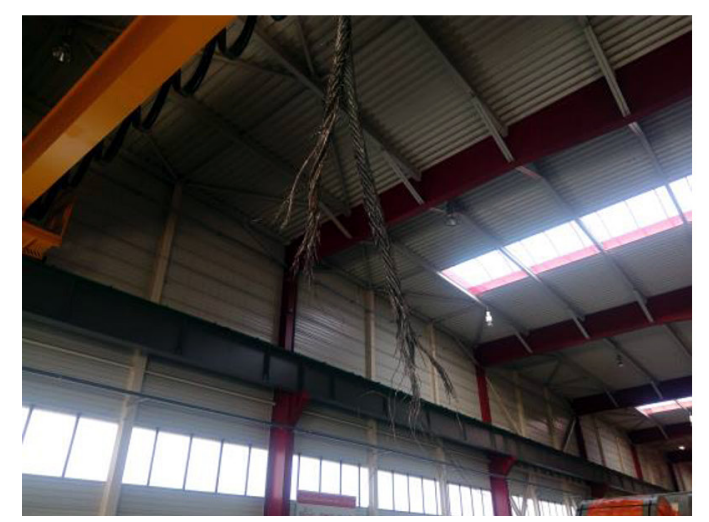

\section{MATERIAL AND METHODS}

The NDT measurement was performed by a magneto-inductive defectoscopic device fitted with scanning coils. The instrument was applied on the individual branches of the crane pulley system in order to record the maximum possible length of the hoist rope.

The coil sensors were of two different constructions - narrow and wide. The scanning coil diameters with maximum spacing $2 \mathrm{~mm}$ from the rope were used for the measurement.

\section{RESULTS}

In practice rope inspections can be conducted according to the Standard ISO 4309 listing the cri-

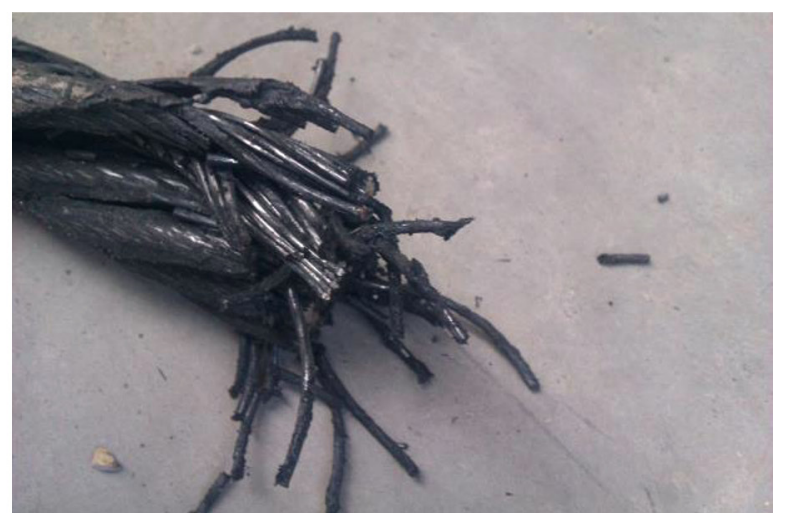

Fig. 2. The abruption of the rope in service 
teria used for the inspection and storage of steel ropes. A damage to the rope usually occurs due to a number of factors whose detection and gradual removal, respectively elimination will lead to the extension of the rope lifetime and it will increased safety at work. One of the significant elements increasing safety at work is introduction of regular non-destructive inspections of steel ropes. The intensive use of cranes, the introduction of new constructions of cranes and steel ropes have also affected the approach to the inspections of steel ropes used on cranes. The non-destructive inspection providing information on the general condition of the rope must be considered relevant. The visual examination of the external surface of the rope is insufficient according to our previous experience. The employment of the ropes, where the cable core is formed by an individual rope
(IWRC), comes exclusively to the failure development inside of the ropes. The occurrence of the external ruptures is only a final manifestation of a damage to the rope before it breaks (Figure 2).

To obtain the image of the development of rope damage, 156 measurements on 39 cranes in three different plants were carried out. Based on the experience of crane operation, the assessment of their loading and their tractive work and the intervals of the NDT inspections were determined. After the employment of the rope, the initial test was carried out to state the condition of the rope and record the possible damages to the rope originated during the manufacturing process, transport and during the put on process. Figure 3 illustrates the courses of the damage to the crane rope in approximately three-month time intervals. Figure $3 \mathrm{a}$ depicts the initial rope test. There were no breaks

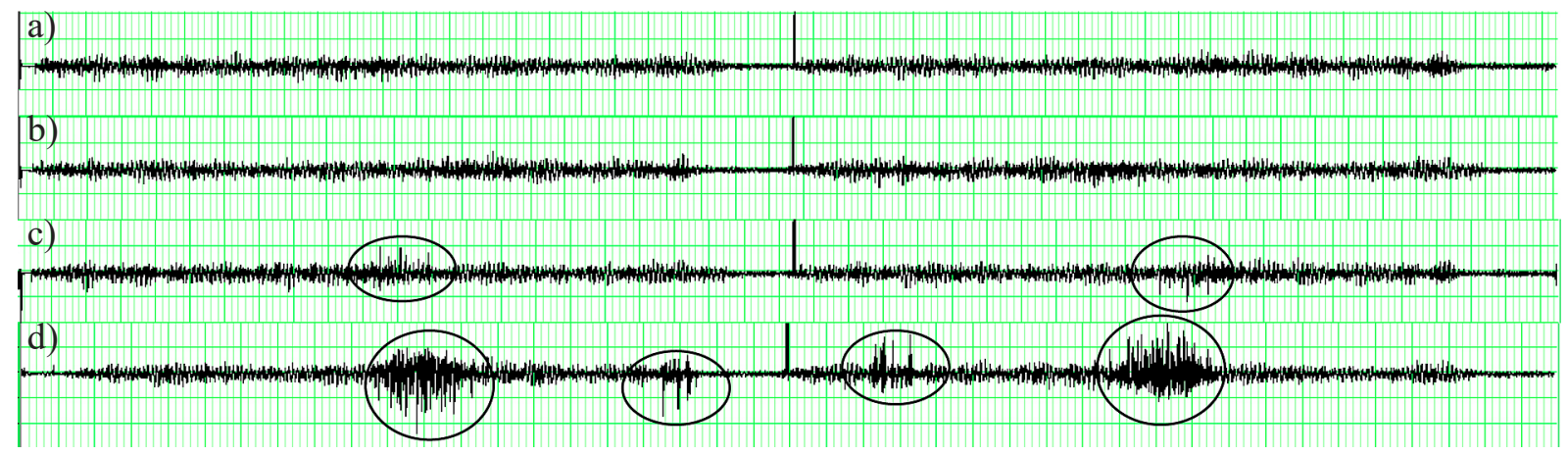

Fig. 3. The progress of the damage of the rope from the selected crane. The NDT records of the selected rope. The record shows both of two directions of the rope motion in the defectoscope (Z00_2014)

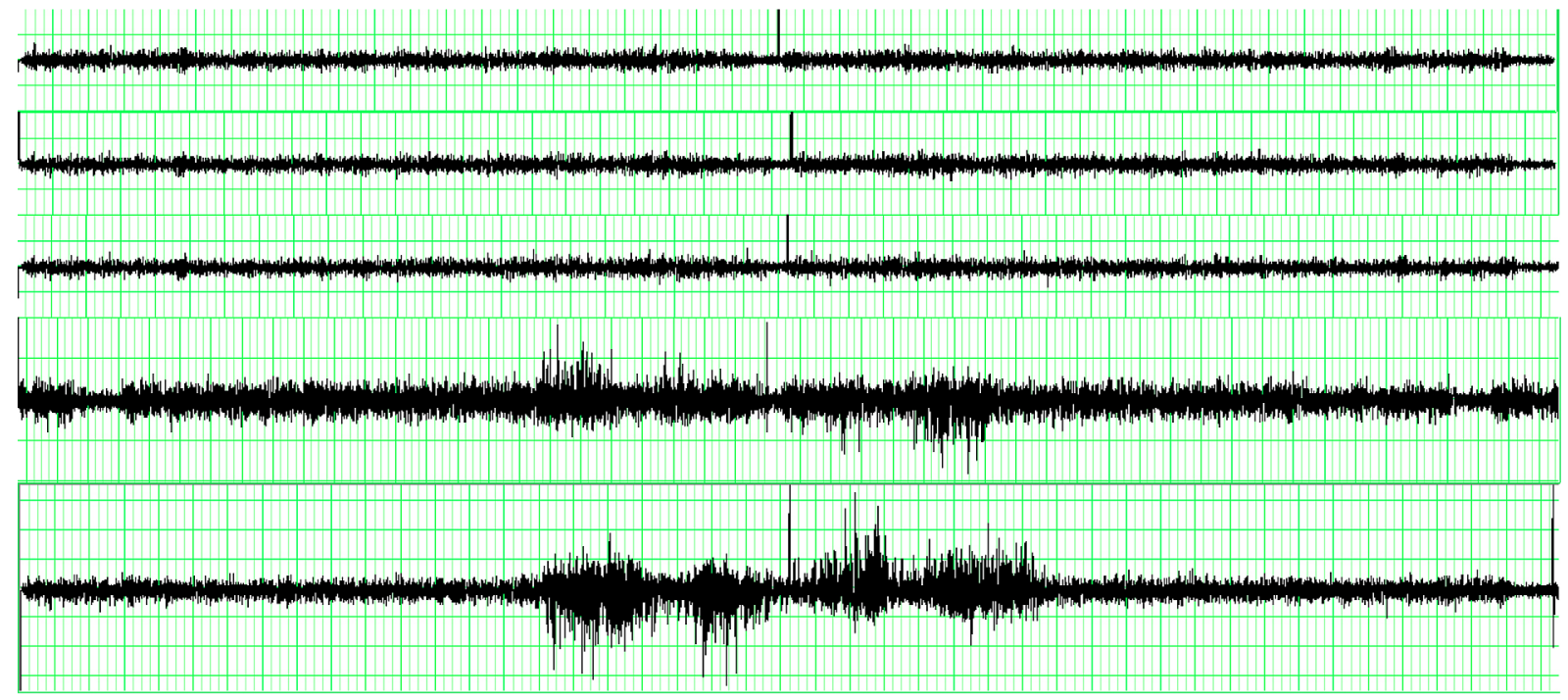

Fig. 4. The progress of the rope damage of the selected crane. The NDT records of the selected rope. The record shows both of two directions of the rope motion in the defectoscopic device (Z01b_2014/15) 
or technological joints of the wires from the manufacturing process of the rope. Figure $3 \mathrm{~b}$ shows the NDT test after 69 days. The recording does not show significantly increased noise in comparison with the record of the initial test. No ruptures on the rope were identified. Figure $3 \mathrm{c}$ represents the NDT test after 162 days of working, first internal disruptions are identified. The subsequent 246-day control is shown in Figure 3d. The record shows two groups of the ruptures formed by the nests of the inner ruptures of the wires. There was no external, visually visible rupture on the rope. The rope was put off after 246 days of working. The similar course of the rope damage can be observed in the records shown in Fig. 4. In this case the rope was put on right one year after the initial rope test after its postponement.

The selected put off ropes were transferred to our laboratory after being wound out of the pulley systems. The repeated defectoscopic revision was carried out, than the subsequent unweaving of the rope and the documentation of the course of its damage (Figures 5 and 6) were performed.

\section{DISCUSSION}

It turns out that the number of inspected cranes working in various plants has been increasing in the course of last ten years. Nowadays more than a half of work of our laboratory is represented by tests and inspections of bridge cranes steel ropes.

The controlled ropes are of different construction, but all of them have one component in common - their cable core is made of an individual steel rope. In the past the NDT testing of cranes ropes was focused only on visual inspection. Technicians were accustomed to find fractured wires only on visible parts of the external strands of the ropes, i.e. on the surface of the rope. The employed ropes were the ropes with a textile core. The steel wire ropes were visually inspected in the critical places by opening the rope. Nowadays the ropes with a plastic insert between the strands AS WELL AS between the strands and the core are used; therefore, the above mentioned procedure can-
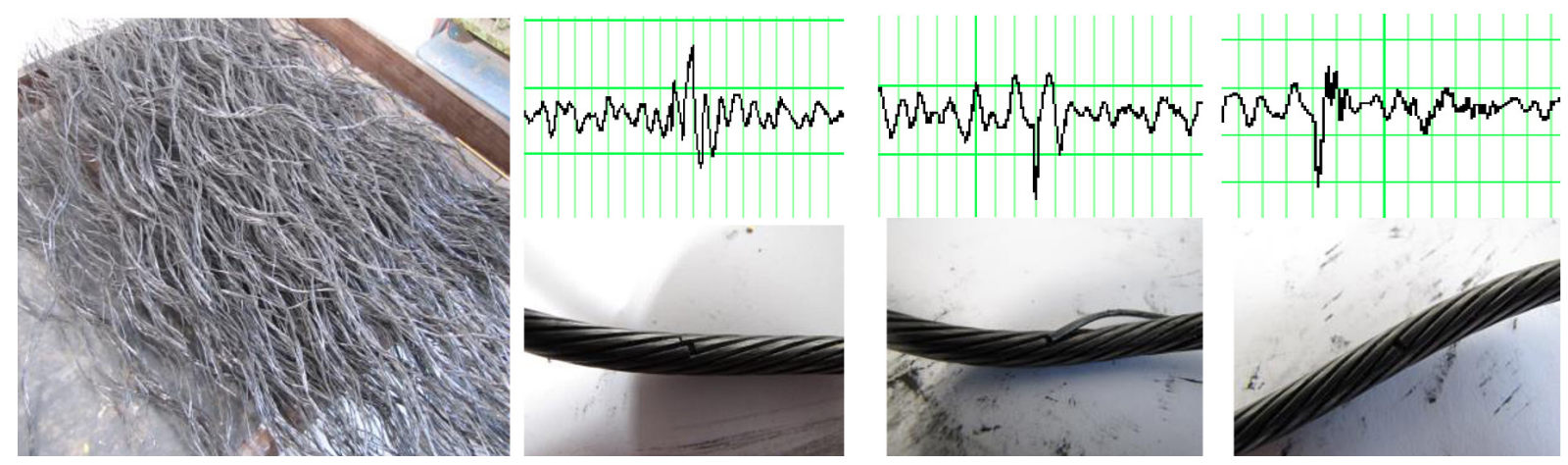

Fig. 5. The rope unweaving and documenting the location of the rope damage

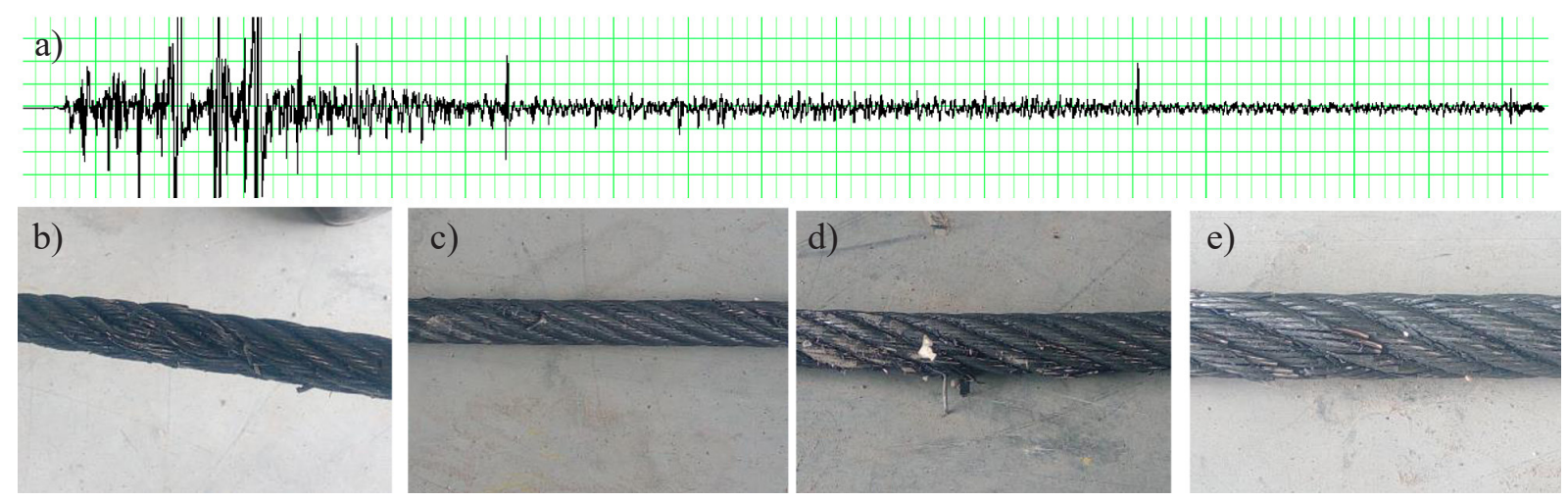

Fig. 6. The damaged rope documentation a) the record of the NDT inspection, b-e) the external ruptures of the rope 
not be used anymore. The majority of our current customers started to consider NDT control as late as the critical situation raised because of the abruption of the rope with a suspended load during manipulation. The subsequent analyses of the broken ropes confirmed the appropriate material the ropes were made of, the depletion and the fatigue of the rope were both identified as a source reason of the damage. In order to establish a NDT system densified the NDT controls were performed for each customer to detect the periodicity of the rope damage due to fatigue. The put off ropes were subjected to the following procedures: repeated NDT measurements, physical identification of the place of the rope breakage, the damaged section of the rope was cut out, unweaving, localization and quantification of the ruptures and their comparison to the NDT records. The safe interval of the NDT checks was established for each customer separately.

The following conclusions are based on the above mentioned tests results :

- inner ruptures arise in ropes with an individual cable core (IWRC);

- These ruptures are located at the place where the outer cable strand comes in the contact with the steel cable core (Figure 7);

- neither the plastic insert separating the cable strands of the rope and nor the outer strands and the individual steel core of the rope will prevent the formation of ruptures;

- the formation of surface ruptures occurs till after the disintegration of the wires inside of the rope at the place where the cable strands and the steel cable core come in the contact;
- after the first external ruptures occur, the abruption of the rope follows in a short time;

- the visual inspections detecting the external fractures are ineffective and they rather should be focussed on potential deformations and changes of the rope cross-section;

- the internal fractures arise in new, diminished construction of the crane crabs and the substandard anchorages (anchoring) of the dead ends of the ropes.

\section{CONCLUSION}

Pursuant to experience from the NDT inspections of the crane ropes carried out since 2011 and the experiments on the postponed ropes it is possible to state that the use of the ropes of the different constructions as well as the constructions of the cranes cause other, different type of stress. Up to now used visual inspection procedures have become ineffective, only the use of the NDT controls by means of the magneto-inductive controls has helped to solve the problem of safety work with cranes. The intensive use of the ropes leads to rather fast fatigue of the ropes, even the high quality input material (validated by mechanical tests) is used for their manufacturing. Apart from the above, it can be stated that the modern crane structures themselves have an effect on the rope lifetime. The pulley deposition in some constructions leads to multi-axis bending and it contributes to the increase of the fatigue effect of the ropes in the system. Incorrect anchoring of the dead end of the rope also contributes to the rope lifetime decrease and the increase of the rope stress and fatigue.

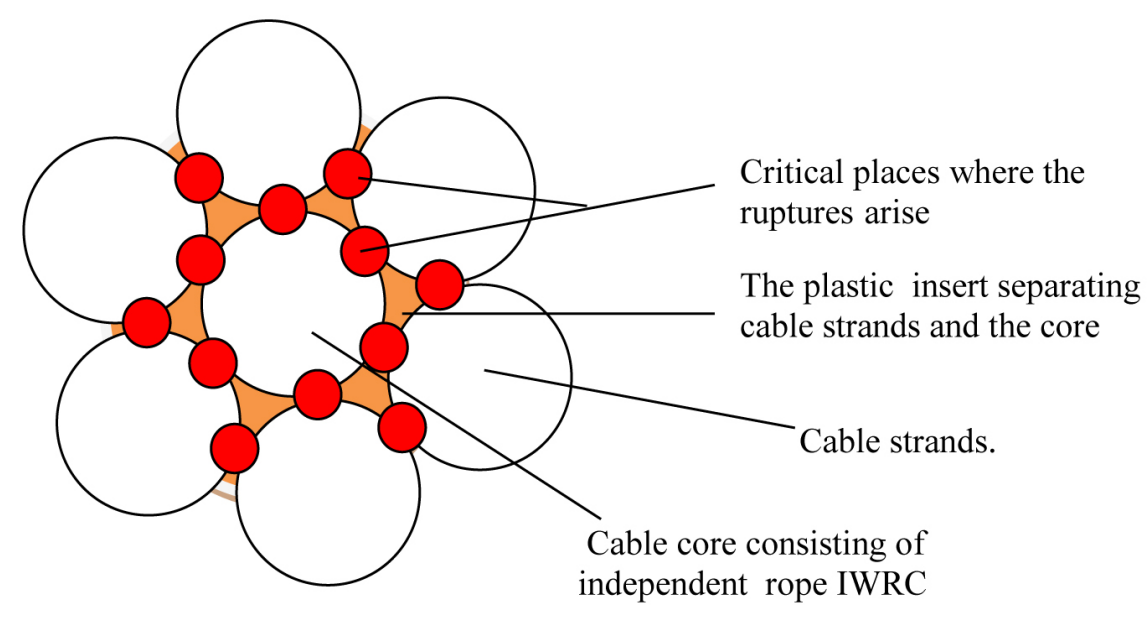

Fig. 7. Representation of the critical place of ruptures formation on the controlled cranes 


\section{Acknowledgements}

Supported by the Scientific Grant Agency (VEGA) of the Ministry of Education of the Slovak Republic and the Slovak Academy of Sciences, Grant No. VEGA 1/0384/16.

The responsible translators and correctors of English language are Viera Nemčoková and Pavel Peterka.

\section{REFERENCES}

1. Yaman O. and Karakose M., Auto Correlation Based Elevator Rope Monitoring and Fault Detection Approach with Image Processing: International artificial intelligence and data processing symposium (IDAP) 2017.

2. Kulka J., Mantic M., Kopas M. and Faltinova E., Assessing the need for rope replacement in crane lifting equipment after change of crane operational parameters: Advances in science and technologyresearch journal 2017, 11(2), 226-230.

3. Kulka J., Mantic M., Faltinova E., Molnar V., Fedorko G., Failure analysis of the foundry crane to increase its working parameters, Eng. Fail. Anal. 88 (2018) 25-34.

4. Kulka J., Mantic M., Kopas M., Faltinova E., Locking the movement of persons on the bridge crane: Advances in science and technology-research journal 2018, 12 (2), 260-265

5. Vukelic G. and Vizentin G., Damage-Induced Stresses and Remaining Service Life Predictions of Wire Ropes: Applied sciences-basel 2017, 7(1), 107.

6. Singh R. P., Mallic M. and Verma M. K., Studies on failure behaviour of wire rope used in underground coal mines: Engineering failure analysis 2016, 70, 290-304.

7. Manka E., Slomion M., Matuszewski M., Constructional features of ropes in functional units of mining shaft hoist: Acta mechanica et automatica 2018, 12(1), 66-71.

8. Hrabovsky. L., Michalik. P., A tension equalizer in lift carrying ropes: Advances in science and technology-research journal 2017, 11 (4), 326-332.

9. Cereska A., Zavadskas E. K., Bucinskas V., Podvezko, V. and Sutinys E., Analysis of Steel Wire Rope Diagnostic Data Applying Multi-Criteria Methods: Applied sciences-basel 2018, 8 (2), 260.

10. Jachowicz T.; Sikora J.; Dulebova L.: Investigating Effects Of Prodegradant Content On Selected Properties Of Polymer Composite Materials. Environ Eng Manag J 2017, 16 (12), 2879-2886.

11. Strohmandl. J. and Tomek M., Possibilities of Reducing Emergency Situations during the Operation of Internal Environmental Transport Systems: Proceedings of the 20th international scientific conference transport means 2016, 729-734.

12. Strohmandl J. and Cempirek M., Experimental Measurements Used to Reduce Emergency Situations of Environmental Continuous Transport: Proceedings of the 20th international scientific conference transport means 2016, 835-839.

13. Zhang W., Zhang D.S., Wang H.Z. and Cheng J.X., Comprehensive Technical Support for HighQuality Anthracite Production: A Case Study in the Xinqiao Coal Mine, Yongxia Mining Area, China: Minerals 2016, 5, 4, 919 - 935.

14. Piskoty G., Affolter C., Sauder M., Nambiar M. and Weisse B., Failure analysis of a ropeway accident focussing on the wire rope's fracture load under lateral pressure: Engineering failure analysis 2017, 82, $648-656$.

15. Zhang D. K., Feng C. A., Chen K., Wang D. G., and Ni X., Effect of broken wire on bending fatigue characteristics of wire ropes: International journal of fatigue 2017, 103, 456 - 465.

16. Molnár V., Boroška J., Dečmanová J., Mechanical properties of steel rope wires -- quality test assurance, Acta Montan. Slovaca. 15 (2010) 23-30.

17. Pawlowski B., Krawczyk J., Bala P., Cios G. and Tokarski T., The analysis of the water-expanded rock bolts ruptures during pressure test: Archives of mining sciences 2017, 62 (2), 423-430.

18. Zhao B., Zhao Z. B., Hua G. and Liu C., A new lowcarbon microalloyed steel wire in drilling rope: Materials science and technology 2016, 32, 7, 722-727.

19. Rudawska A., Debski H., Experimental and numerical analysis of adhesively bonded aluminium alloy sheets joints, Eksploat. I Niezawodn. - Maint. Reliab. (2011) 4-10.

20. Wang S. Q., Zhang D. K., Hu N. N. and Zhang J.L., Effect of Stress Ratio and Loading Frequency on the Corrosion Fatigue Behavior of Smooth Steel Wire in Different Solutions: Materials 2016, 9(9), 750.

21. Chang X.D., Peng Y.X., Zhu Z.C., Gong X.S., YU Y.F., Mi Z.T. and XU C.M., Experimental investigation of mechanical response and fracture failure behavior of wire rope with different given surface wear: Tribology international 2018, 119, 208-221.

22. Guo Y.B., Zhang D.K., Chen K., Feng C. and Ge S. R., Longitudinal dynamic characteristics of steel wire rope in a friction hoisting system and its coupling effect with friction transmission: Tribology international 2018, 119, 731-743.

23. Kou B.F., Liu Q. Z. and Li N., Research on transverse vibration characteristics of rope change device with clamping chain transmission in lifting system: Journal of vibroengineering 2017, 19 (2), 894 - 907. 
24. Flegner P., Kacur J., Durdan M., Laciak M., Stehlikova B. and Pastor M., Significant damages of core diamond bits in the process of rocks drilling: Engineering failure analysis 2016, 59, 354-365.

25. Wang C. M., Wang J. S., Du B., Fang L.T. and Zhang S.L., The Influence to Mine Hoisting Steel Wire Rope Tension and Deformation from Velocity and Acceleration: International conference on manufacturing science and information engineering (ICMSIE 2016) 2016, 296-306.

26. Wang J.S., Wang C.M. and Du B., The influence to mine hoisting steel wire rope tension and deformation from load and elastic modulus: Proceedings of the 5 th international conference on civil engineering and transportation 2015, 30, 1627-1635.

27. Peng Y.X., Chang X.D., Sun S.S., Zhu Z.C., Gong X.S., Zou S.Y., Xu W.X. and Mi Z.T., The friction and wear properties of steel wire rope sliding against itself under impact load: Wear 2018, 400, 194-206.

28. Liang B., Zhao Z.W., Wu X.F. and Liu H. Q., The establishment of a numerical model for structural cables including friction: Journal of constructional steel research 2017, 139, 424-436.
29. Peng Y.X., Chang X.D., Sun S.S., Zhu Z.C., Gong X.S., Zou S.Y., Xu W.X., Mi Z.T., The friction and wear properties of steel wire rope sliding against itself under impact load: WEAR, 400, 194-206.

30. Vaclav S., Sivtsev N.S. and Senderska K., Investigation of stress-strain state of a workpiece at gauge burnishing of its holes: Advances in science and technology-research journal 2017, 11, 211-222.

31. Kalentev E., Vaclav S., Bozek P., Tarasov V. and Korshunov A., Numerical analysis of the stressstrain state of a rope strand with linear contact under tension and torsion loading conditions: Advances in science and technology-research journal 2017, 11, 211-222.

32. Ivanco V., Kmet S., Fedorko G., Finite element simulation of creep of spiral strands, Eng. Struct. $117,2016,220-238$.

33. Lonkwic P., Rozylo, P., Debski, H. Numerical and experimental analysis of the progressive gear body with the use of finite-element method. Eksploatacja i Niezawodnosc - Maintenance and Reliability, 2015 17(4), pp. 544-550. 